\title{
Comunicación
}

\section{IMPACTACIÓN FECAL EN UNA BOA (Boa constrictor) - REPORTE DE CASO}

\author{
Fecal Impaction in a Python (Boa constrictor) - Case Report
}

\author{
Isaac Manoel Barros Albuquerque ${ }^{1}$, David Montes Iturrizaga ${ }^{2}$, Eduarda Mendes \\ Almeida $^{1}$, Jairo de Macedo Lins Silva Neto ${ }^{3}$
}

\section{Resumen}

Se reporta el caso de una boa (Boa constrictor) adulta llevada a consulta por presentar un cuadro de anorexia, letargo y ausencia de deposiciones por dos meses. Según la historia, el ejemplar se alimentaba de pequeños anfibios, ratas y carne molida. En el examen físico se palpó una distensión firme de la cavidad celómica. Mediante radiografía simple se detectaron 13 estructuras radiopacas ocupando el tercio final de la cavidad celómica del animal. Se diagnosticó obstrucción intestinal por fecalomas. Se le trató inicialmente con aceite mineral oral y transrectal sin éxito. El animal fue sometido a una enterotomía y se logró retirar 365 g de contenido fecal. Después de la cirugía, se administró un tratamiento con antibioticoterapia a base de enrofloxacina $(10 \mathrm{mg} / \mathrm{kg}, \mathrm{i} . \mathrm{m})$ y ketoprofeno $(2 \mathrm{mg} / \mathrm{kg}$, i.m.) como antiinflamatorio; además, se administró aceite mineral $(1 \mathrm{mg} / \mathrm{kg})$ por vía oral para favorecer el tránsito intestinal.

Palabras clave: fecaloma, anorexia, Boa constrictor

\section{Abstract}

It is reported the case of an adult python (Boa constrictor) with signs of anorexia, lethargy and no bowel movements for about two months. According to the clinical history, the animal was fed with small amphibians, rats and ground beef. On the clinical evaluation was palpated a firm distention of the coeloic cavity. Through simple radiography was detected 13 radiopaque structures in the final third of the coelomic cavity. The diagnosis was intestinal obstructions due to fecalomas. The initial treatment consisted

${ }^{1}$ Centro Universitario Cesmac, Maceió, Alagoas, Brasil

${ }^{2}$ Facultad de Veterinaria y Zootecnia, Universidad Peruana Cayetano Heredia, Lima, Perú

${ }^{3}$ Universidad Federal Rural de Pernambuco, Garanhuns, Pernambuco, Brasil 
in oral and transrectal mineral oil; however, without success. Then, an enterotomy was performed and $365 \mathrm{~g}$ of fecal content was removed. After surgery, antibiotic therapy using enrofloxacin $(10 \mathrm{mg} / \mathrm{kg}$, im) and ketoprofen $(2 \mathrm{mg} / \mathrm{kg}$, im) as anti-inflammatory were administered. Also, mineral oil was orally administered $(1 \mathrm{mg} / \mathrm{kg})$ to promote intestinal transit.

Keywords: fecaloma, anorexia, Boa constrictor

\section{INTRODUCCIÓN}

La constipación no es una enfermedad sino un signo clínico caracterizado por la ausencia de defecación y la retención de heces en el colon y recto (Rajagopal y Martin, 2002; Birchard y Sherding, 2003; Hedlund y Fossum, 2008), acompañado generalmente de disquecia. Cuando las heces son retenidas por un periodo prolongado, la mucosa intestinal continua absorbiendo agua, solidificando, resecando y deshidratando la masa fecal, formando concreciones que pueden tornarse muy grandes al grado de dificultar su eliminación y producir dolor (Birchard y Sherding, 2003; Hedlund y Fossum, 2008). La distensión abdominal causada por la masa fecal puede producir alteraciones irreversibles en el tejido muscular y nervios del colon, llevando a la falta de motilidad y consecuentemente a la absorción de toxinas bacterianas, responsables de los signos de depresión, anorexia y debilidad (Hedlund y Fossum, 2008).

Los cuadros de constipación intestinal pueden presentarse por infecciones y tumores intestinales, bajo consumo de agua (Dart et al., 1997; Hedlund y Fossum, 2008), bajas temperaturas y humedad, ingestión de material extraño y dietas inadecuadas, entre otros, así como ser secundaria por compresión del colon por masas fuera de la luz intestinal (órganomegalias, granulomas o urolitos) (Birchard y Sherding, 2003; Hedlund y Fossum, 2008).
Las boas se incluyen en el Suborden Ophidia. Se alimentan de mamíferos pequeños y de aves, así como de otros reptiles. No despedazan a sus presas sino que las engullen enteras, de allí que su metabolismo está adaptado para realizar una digestión lenta y con regurgitación de materiales no digeribles como pelos, plumas y huesos (Cubas et al., 2006).

Las boas y, en general, los reptiles son animales poiquilotermos; es decir, no presentan un mecanismo interno que regule la temperatura corporal, dependiendo exclusivamente del ambiente donde se encuentre (Randall et al., 2002; Oliveira, 2003). Estos animales deben mantener la llamada temperatura óptima, que es aquella donde el metabolismo del animal funciona de la mejor forma, y que generalmente está entre 24 y $30{ }^{\circ} \mathrm{C}$ (Carpenter, 2005).

Los signos clínicos de la impactación fecal van desde una disminución de la producción fecal hasta signos de obstrucción gastrointestinal, tales como anorexia y vómito. Además, el animal puede presentarse caquéctico, hipotérmico y deshidratado. En estadios iniciales, la palpación de la cavidad celómica puede revelar una masa de consistencia firme a flácida y el colon distendido. Como examen complementario, la radiografía permite delimitar la obstrucción, mostrando un colon impactado y distendido con masa fecal, pudiéndose descartar la posibilidad de dolencias obstructivas (Birchard y Sherding, 2003; Hedlund y Fossum, 2008). 

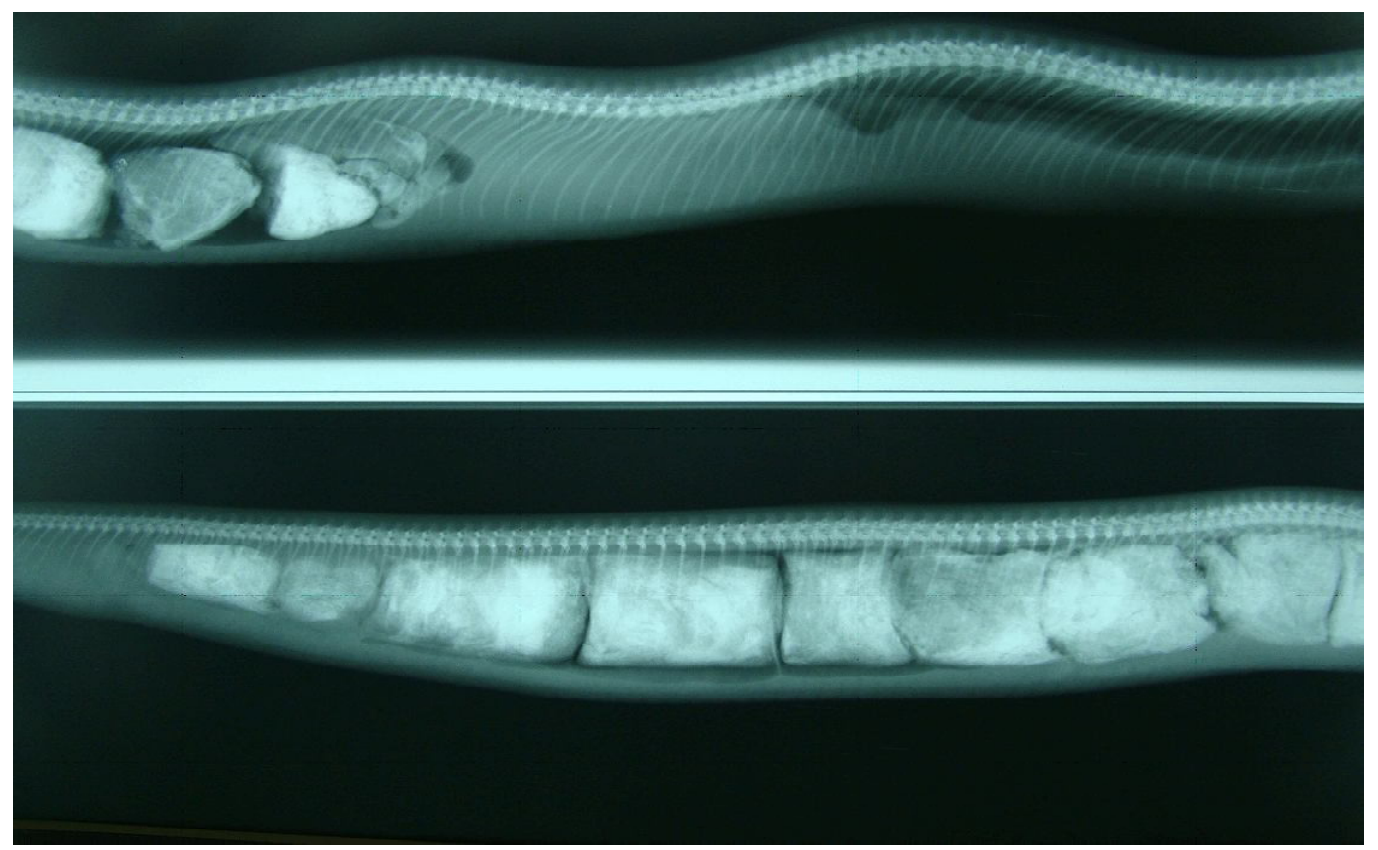

Figura 1. Radiografía de una boa (Boa constrictor) adulta con 13 fecalomas en el tercio final del intestino grueso

Una vez diagnosticada la constipación, la conducta médica inicial incluye la corrección de los desequilibrios hídrico, electrolítico y ácido-base, así como la evacuación de heces con auxilio de emolientes, enemas o evacuación digital. El uso de antibióticos paliativos puede proteger al animal contra la absorción sistémica de bacterias y sus toxinas (Hedlund y Fossum, 2008).

\section{REPORTE}

Un ejemplar de boa (Boa constrictor), hembra, adulta, con $2.7 \mathrm{~kg}$ de peso, fue llevada a la clínica de animales silvestres de un hospital veterinario privado de la ciudad de Maceió, Alagoas, Brasil. El ejemplar provenía de una crianza ilegal, alimentándose de pequeños anfibios y carne bovina molida. Su terrario estaba en un local con poco o ningún acceso directo de los rayos solares, lo cual generaba una temperatura ambiental de 20 a $22{ }^{\circ} \mathrm{C}$.
El animal presentaba un cuadro de anorexia y letargia, y el dueño informó que no había defecado por dos meses. En el examen físico se evidenció a la palpación una distensión firme de la cavidad celómica. Se tomó una placa radiográfica simple y se detectaron 13 estructuras radiopacas ocupando el tercio final de la cavidad celómica del animal (Fig. 1). El diagnóstico fue de obstrucción intestinal por fecalomas.

El animal fue sometido a un tratamiento con antibioticoterapia a base de enrofloxacina (10 mg/kg, i.m.) y ketoprofeno ( $2 \mathrm{mg} / \mathrm{kg}$, i.m.) (Carpenter, 2005) como antiinflamatorio. Además, se administró aceite mineral $(1 \mathrm{mg} /$ $\mathrm{kg}$ ) (Carpenter, 2005), vía oral y transrectal, y se le mantuvo a una temperatura ambiental de $25{ }^{\circ} \mathrm{C}$. Asimismo, se hicieron masajes en sentido cráneo-caudal para estimular la defecación. 


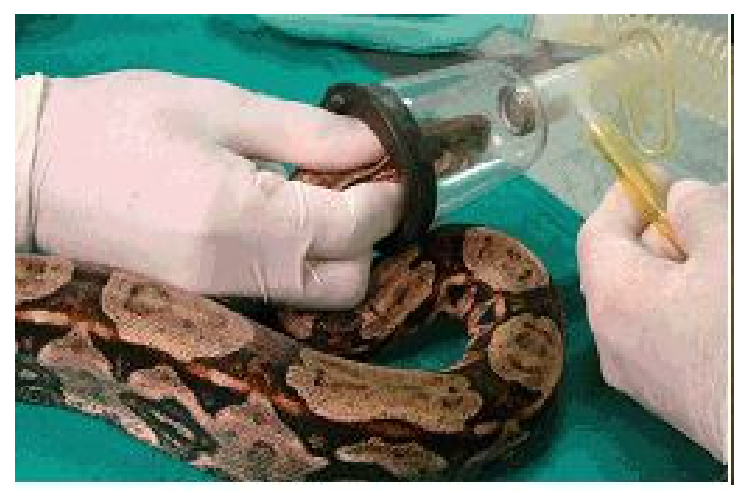

(a)

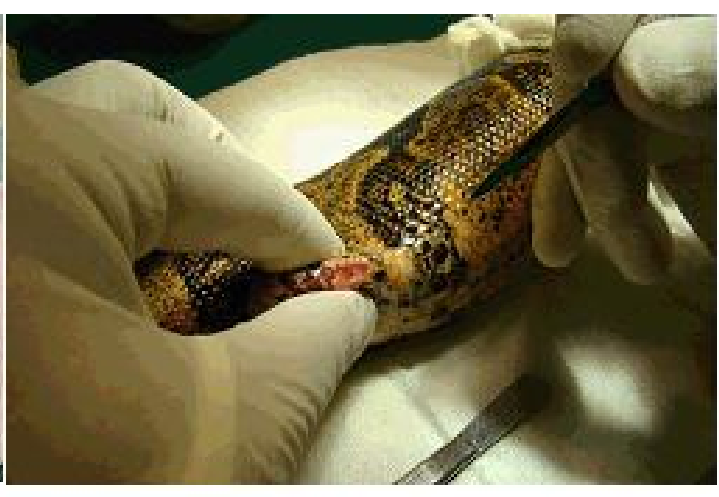

(b)

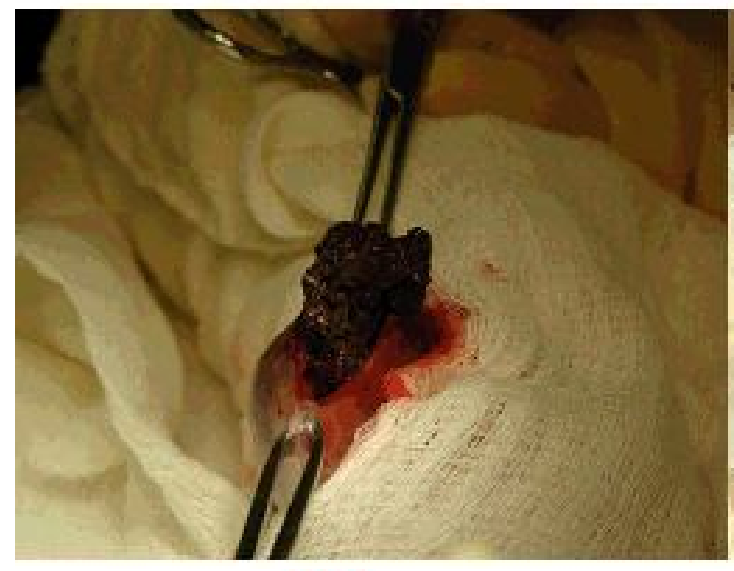

(c)

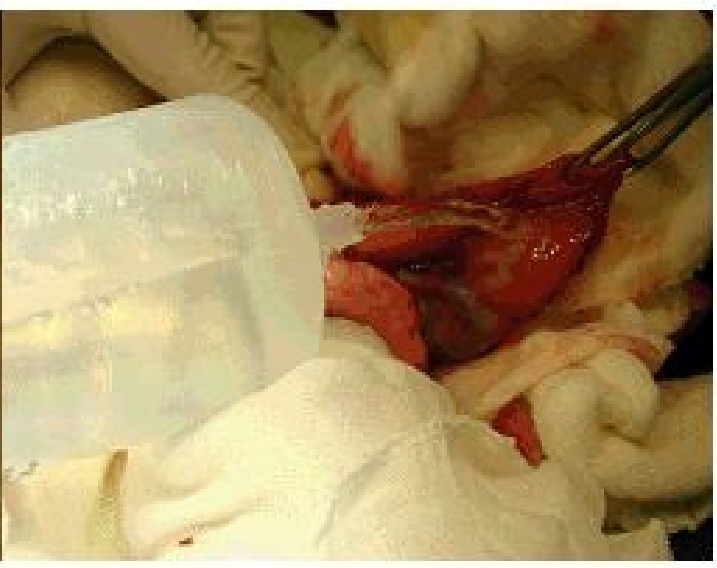

(d)

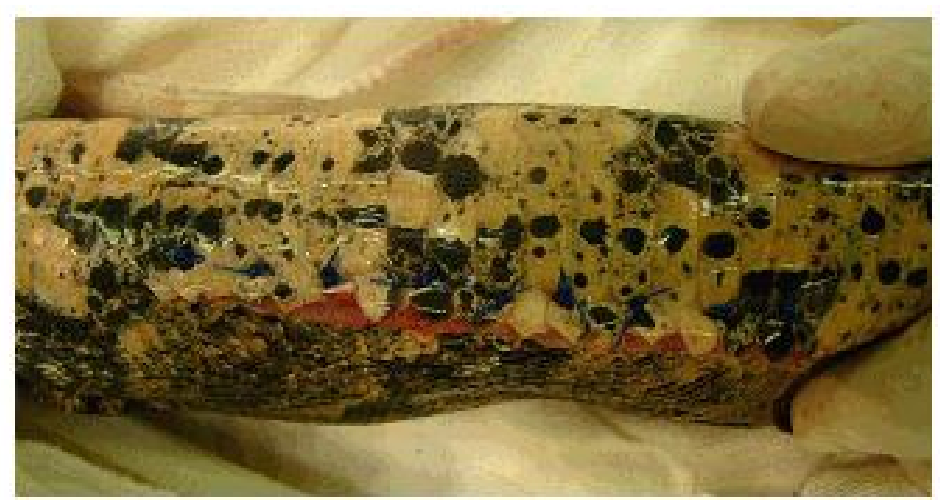

(e)

Figura 2. Anestesia y cirugía en una boa (Boa constrictor) adulta con impactación fecal en el intestino grueso. a) Mantenimiento de la anestesia con máscara inhalatoria de isoflurano; b) Incisión lateral de piel conservando las escamas; c) Exteriorización del contenido fecal; d) Lavado de las asas intestinales y de la cavidad celómica con solución fisiológica a $0.9 \%$; e) Sutura de piel con patrón Wolff discontinuo 
Después de tres días de tratamiento clínico sin aparente éxito, se optó por el tratamiento quirúrgico. La inducción anestésica se realizó con clorhidrato de ketamina $(40 \mathrm{mg} /$ $\mathrm{kg})$ y diazepam $(0.4 \mathrm{mg} / \mathrm{kg})$ (Carpenter, 2005) por vía intramuscular. Una vez ocurrida la pérdida del reflejo de enderezamiento postural (RPE), se optó por el uso de isoflurano a través de máscara facial (Fig. 2a). Además, el animal fue mantenido bajo calefacción con un colchón térmico durante toda la fase de anestesia y cirugía.

Se hizo la antisepsia con alcohol y yodo, se efectuó una incisión de la piel en la región lateral izquierda, entre las escamas dorsales y ventrales (Fig. 2b), respetando la morfología de las mismas. Se exteriorizó el asa intestinal y se procedió a realizar una enteroctomía para lo cual se incidió en la porción craneal del intestino grueso. Se extrajo el contenido fecal llegándose a remover 365 g (Fig. 2c) con auxilio de masajes con compresión en sentido caudo-craneal. En el contenido fecal se visualizó la presencia de pelos.

El intestino fue lavado con solución salina estéril $0.9 \%$ (Fig. 2d). Se hizo una primera sutura con hilo absorbible de ácido poliglicólico («vicryl») 3.0 con sutura simple continua, y luego se reforzó con el mismo hilo en patrón de sutura Cushing y, finalmente, la porción intenstinal fue devuelta a la cavidad celómica. Para la síntesis muscular se utilizó hilo absorbible «vicryl» 2.0 con sutura simple continua y para la piel se usó hilo no absorbible de polipropileno 2.0 en patrón Wolff discontinuo (Fig. 2e).

En el tratamiento post-operatorio se aplicó ketoprofeno y enrofloxacina en las mismas dosis aplicadas en el tratamiento clínico, y se mantuvo la temperatura ambiental alrededor de $25{ }^{\circ} \mathrm{C}$, aunque no fue posible controlar la humedad ambiental. La sutura de piel fue retirada a los 10 días, luego de verificarse la buena cicatrización de la herida y el buen estado físico y clínico del ani- mal. Todo el procedimiento, desde la llegada del animal, fue ejecutado en el hospital.

El manejo inadecuado, tanto del hábitat como de la alimentación, es una de las causas más frecuentes de patologías digestivas en reptiles en cautiverio (Bennett, 1991; Silva et al., 2003; Franch et al., 2009). En el presente caso, el animal presentó una condición de constipación por fecalomas relacionada a la mala alimentación recibida y a la inadecuada temperatura ambiental.

El tratamiento quirúrgico es el más eficaz y seguro en los casos de obstrucción intestinal por fecalomas. El protocolo anestésico utilizado resultó eficaz, rápido y seguro, además de promover un retorno tranquilo para el animal. Por otro lado, además del protocolo anestésico, el control de la temperatura corporal durante la anestesia y posterior a la cirugía es de gran importancia, ya que un estado hipotérmico no proporciona analgesia, retarda la cicatrización y deprime el sistema inmune (Birchard y Sherding, 2003).

\section{Literatura Citada}

1. Bennett RA. 1991. A review of anesthesia and chemical restraint in reptiles. J Zoo Wildlife Med 22: 282-303.

2. Birchard S, Sherding R. 2003. Manual Saunders: Clínica de pequenos animais. $2^{\circ}$ ed. São Paulo: Roca. 1591 p.

3. Carpenter JW. 2005. Exotic animal formulary. $3^{\circ}$ ed. Missouri: Elsevier Saunders. 496 p.

4. Cubas Z, Silva J, Catão-Dias J. 2006. Tratado de animais selvagens - medicina veterinária. São Paulo: Roca. 1354 p.

5. Dart AJ, Hpdgson DR, Snyder JR. 1997. Caecal disease in equids. Aust Vet J 75: 552-557.

6. Franch J, Martorell J, Lafuente P. 2009. Resolución quirúrgica de una obstrucción intestinal por impactación fecal 
en un varano (Varanus exanthematicus). [Internet], [20 octubre 2009].

Disponible en: http://minnie.uab.es/ $\sim$ veteri/21232/varano.pdf

7. Hedlund CS, Fossum TW. 2008. Cirurgia do sistema digestório. In: Fossum TW (ed). Cirugia de pequenos animais. $3^{\circ} \mathrm{ed}$. Rio de Janeiro: Elsevier. p 339-530.

8. Oliveira P. 2003. Animais silvestres e exóticos na clínica particular. São Paulo: Roca. 375 p.
9. Rajagopal A, Martin J. 2002. Giant fecaloma with idiopathic sigmoid megacolon: Report of a case and review of the literature. Dis Colon Rectum 45: 833-835.

10. Randall D, Burggren W, French $K$. 2002. Eckert animal physiology: mechanisms and adaptations. $5^{\circ}$ ed. New York: WH Freman. 736 p.

11. Silva F MO, Simões-Mattos L, Mattos MRF. 2003. Fecaloma em um quati (Nasua nasua): Relato de caso. Ciência Anim 13(2): 73-77. 